\title{
Dieulafoy's disease controlled by Doppler ultrasound endoscopic treatment
}

\author{
D Jaspersen
}

\begin{abstract}
Dieulafoy's disease is a gastric vascular malformation, that presents clinically as acute upper intestinal haemorrhage. Emergency endoscopy is the most effective method of diagnosing the disease. Until recently surgical resection was the most usual treatment. A case is reported of Dieulafoy's lesion with haemodynamically relevant bleeding. Successful endoscopic treatment was performed with the aid of Doppler ultrasound. A follow up of 11 months with no haemorrhaging was recorded. (Gut 1993; 34: 857-858)
\end{abstract}

\section{Case report}

A 58 year old man presented with severe haematemesis. The patient was in good health and did not have peptic ulcer disease. Emergency endoscopy showed a small ulcer along the lesser gastric curvature $2 \mathrm{~cm}$ below the gastrooesophageal junction. The lesion was $3 \mathrm{~mm}$ in diameter and showed an eroded large vessel stump of $2 \mathrm{~mm}$ in diameter protruding into the lumen (Fig 1). Bleeding had stopped spontaneously at the endoscopic examination.

Transendoscopic Doppler ultrasound was performed using a $20 \mathrm{MHz}$ microvascular Doppler device (MF 20, Eden Medical Electronics, Überlingen, Germany). The flexible Doppler probe $(1.6 \mathrm{~mm}$ in diameter $)$ was passed down the biopsy channel of the endoscope and was positioned under direct vision over the lesion. The arterial blood flow was confirmed by an audible Doppler signal and the curve recorded (Fig 2). Epinephrine (5 $\mathrm{ml} \mathrm{1:10000)}$ and polidocanol ( $3 \mathrm{ml}$ of $1 \%$ ) were injected around and into the visible vessel to prevent rebleeding. After prophylactic sclerosing biopsy specimens were taken (Fig 3).

The patient was monitored carefully for recurrent haemorrhage and controlled by endoscopy every day. No rebleeding occurred and Doppler control detected no further arterial signals from the ulceration. Histopathological examination showed parts of an abnormal artery with erosion and a new thrombus. There was no evidence of vasculitis, atherosclerosis or aneurysm formation. The ulceration healed completely within two weeks and the patient was discharged on day 16. There was no relapse bleeding during the 11 month follow up period.

Department of Gastroenterology, Academic Medical Hospital, Fulda, Germany

D Jaspersen

Correspondence to: Dr D Jaspersen, Academic Medical Hospital, Pacellialle 4-6, W-6400 Fulda, Germany.

Accepted for publication 22 September 1992

\section{Discussion}

Dieulafoy's disease has been given many names, including 'calibre persistent artery of the stomach', 'cirsoid aneurysm', 'gastric arteriosclerosis', and 'peptic ulcer of peculiar location'. 'Dieulafoy's vascular malformation' is the cur-

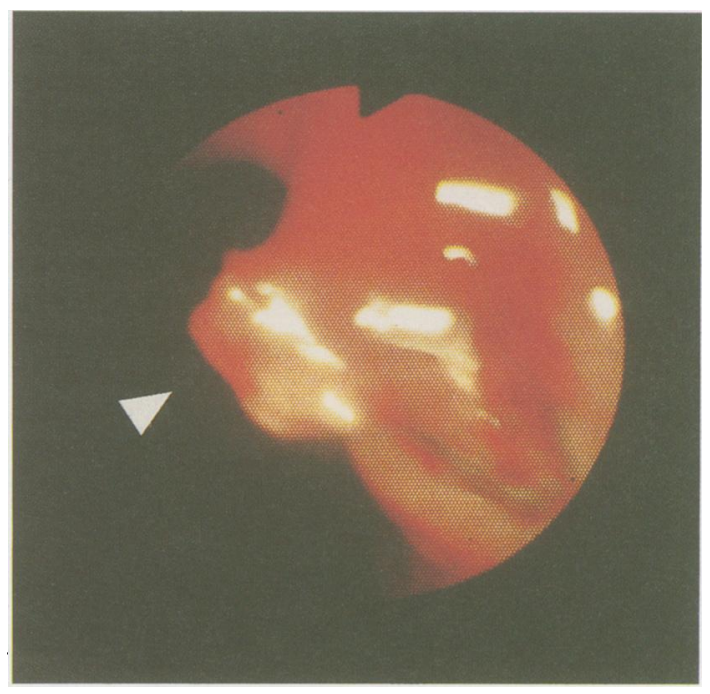

Figure 1: Endoscopic view of the Dieulafoy's vessel stump.

rently accepted term. ${ }^{12}$ It was first discovered by Gallard in $1884,{ }^{3}$ but credit has been given to Dieulafoy who described it in $1889 .{ }^{4}$ Dieulafoy believed that this lesion was an early stage of peptic ulceration, designating it 'Exulceratio simplex' ${ }^{4}$ More recently, it has been interpreted as a congenital anomaly related to defective arterial involution. This lack of involution results in so called calibre persistent submucosal arteries. $^{25}$

The affected vessel is tortuous and enlarged, about $1.5 \mathrm{~mm}$ in diameter. In contrast, the overlying mucosal ulcer is typically small, usually 2 to $5 \mathrm{~mm}$ in diameter. In more than $80 \%$ of cases the site of bleeding is found within $6 \mathrm{~cm}$ of the gastro-oesophageal junction, particularly along the lesser curvature. ${ }^{2}$ The subsequent events that lead to the rupture of these abnormal vessels are unclear. It was previously hypothesised that the rupture was related to degenerative changes in the vessel wall, but structura evidence for this conclusion has not been found.

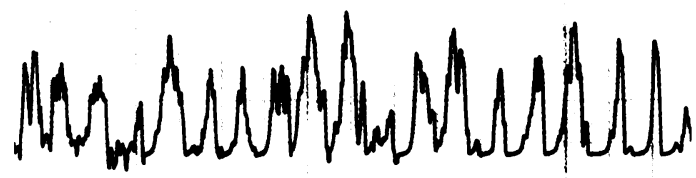




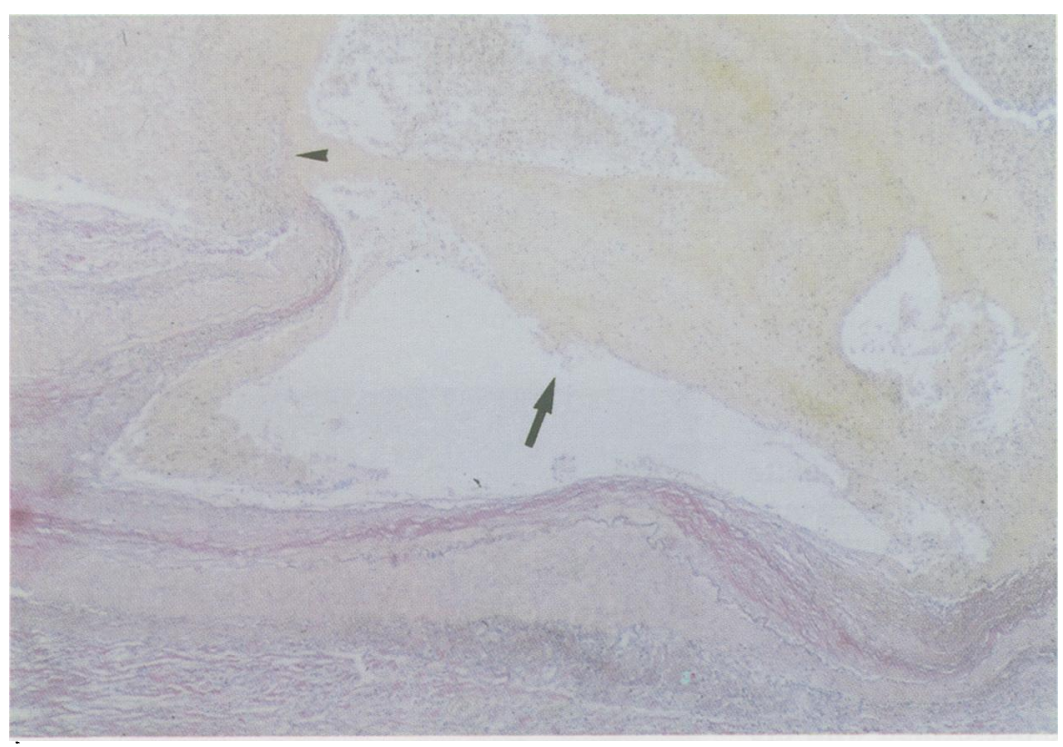

Figure 3: Biopsy specimen taken from the exulceratio simplex Dieulafoy (parts of an abnormal artery with erosion $\triangle$ and new thrombus $\uparrow$ ). (Elastica van Gieson 40×.)
Although thrombosis of the enlarged arteries is generally believed to precede mucosal breakdown, ${ }^{5}$ some authors regard the ulceration as the primary event in the pathogenesis of the arterial rupture. ${ }^{6}$

The pathological features of Dieulafoy's vascular malformation are controversial. Histological examination shows medial hypertrophy and adventitial fibrosis. The wall of the artery has a normal architecture without signs of vasculitis, atherosclerosis or aneurysm formation. ${ }^{7}$ Mucosal erosion as a result of the artery protruding into the overlying mucosa or focal gastritis leads to an exposure of the vessel and results in bleeding. ${ }^{1}$ The haemorrhage is massive because the ruptured artery is usually large. Repeated bleeding at short intervals is the common pattern if the patient survives the initial haemorrhage. ${ }^{\prime}$

The condition usually affects middle aged and elderly men. The median age of the patients is 54 and men are affected twice as often as women. The disorder has no familial tendency. Massive haematemesis or, less commonly, melaena, without previous gastrointestinal symptoms, is the typical presentation. Epigastric pain is uncommon and concurrent peptic ulcer disease may lead to an incorrect diagnosis.'

Since its initial description over a century ago fewer than 150 cases of Dieulafoy's disease have been reported. The lesion is known to be easily overlooked and unrecognised, rather than being rare.' Before the endoscopic era, the diagnosis was rarely made before operation or even at the time of operation and recurrent haemorrhage with a fatal outcome was common. At present the preferred diagnostic procedure is emergency endoscopy. The lesion is not always easily detected on endoscopic examination, especially when it is not actively bleeding. The lesion has been described as a volcano with central whitish discoloration projecting from an otherwise normal gastric mucosa. Or it may appear as an eroded large artery protruding into the lumen. ${ }^{8}$

The endoscopic Doppler ultrasound may be of diagnostic value in the evaluation of Dieulafoy's disease when bleeding has stopped spontaneously. ${ }^{9}$ This method has proved its efficiency in gastroduodenal ulcer bleeding. ${ }^{1011}$ The Doppler allows identification of submucosal arteries inducing haemorrhage. ${ }^{10}$ The technique is also suitable for studying the effectiveness of local endoscopic treatment. Since 1988 the Doppler technique has been used in diagnosing vascular malformations. ${ }^{12}$

Until recently, surgery has been the only effective management for Dieulafoy's lesions. Successful endoscopic management of gastric Dieulafoy's ulcer bleeding was first reported by Pointner et al. ${ }^{8}$ In that series, however, 18 of 22 patients were treated with endoscopy without performing Doppler ultrasound investigation. An attempt was made to stop the bleeding or to prevent further haemorrhage by local injection of polidocanol. All patients made an uncomplicated recovery and none suffered from relapse bleeding after discharge from hospital. Based on these findings the Doppler controlled injection treatment of Dieulafoy's disease could be considered an alternative to surgery.

I would like to thank Dr F Birke and Professor Dr R Bässler from the Pathologic Institute of the Academic Medical Hospital, Fuld for kind permission to publish Figure 3 .

1 Rustgi AK, Compton CC. A 76 year old man with recurren gastrointestinal bleeding. $N$ Englf Med 1991; 325: 1086-96.

2 Veldhuyzen von Zanten SJO, Bartelman JFWM, Schippe MEI, Tytgat GNJ. Recurrent massive haematemesis from Dieulyfoy vascular malformation - a review of 101 cases. $G u$ 1986; 27: 213-22.

3 Gallard T. Aneurysmes miliaires de l'estomac donnant lieu à des hématémèses montelles. Bull Soc Méd Paris 1884; 1: 84 91.

4 Dieulafoy G. Exulceratio simplex: l'intervention chirurgicale dans les hématémèses foudroyantes consécutives l'exulcération simplex de l'estomac. Bull Acad Méd 1889,

5 Juler GL, Labitzke HG, Lamb R, et al. The pathogenesis of Dieulafoy's gastric erosion. Am $\mathcal{F}$ Gastroenterol 1984; 79. 195-200.

6 Goossens A, Pipeleers-Marichal M, Peters O, et al. Solitary exulceration simplex (ulcer of Dieulafoy). Acta Chir Belg 1989; 89: $54-7$.

7 Mortensen NJMC, Mountford RA, Davies JD, et al. Dieulafoy's disease: a distinctive arteriovenous malformation causing massive gastric haemorrhage. $\mathrm{Br} \mathcal{F}$ Surg 1983 70: 76-8.

8 Pointner R, Schwab G, Konigsrainer A, et al. Endoscopic treatment of Dieulafoy's disease. Gastroenterology 1988; 94: 563-6.

9 Jaspersen D. Diagnostics and treatment of Dieulafoy's disease. Dtsch Med Wochenschr 1992; 117: 1447-9.

10 Jaspersen D. Endoscopic Doppler sonography. Dtsch Med Wochenschr 1991; 116: 1966-70.

11 Kohler B, Riemann JF. The endoscopic Doppler: Its value in evaluating gastroduodenal ulcers after hemorrhage and as an instrument of control of endoscopic injection therapy. Scand F Gastroenterol 1991; 26: 471-6.

12 Rutgeerts P, Vantrappen G, D'Heygere F, Broeckaert L. Transendoscopic Doppler ultrasound: Usefulness for diag nosis and treatment of vascular malformations. Endoscopy 1988; 20: 99-101 